\title{
The role of macrophage cell death in tuberculosis
}

\author{
Hardy Kornfeld ${ }^{1}$, Giorgio Mancino ${ }^{2,3}$ and Vittorio Colizzi, ${ }^{\star}{ }^{, 2,3}$ \\ ${ }^{1}$ The Pulmonary Center, Boston University School of Medicine, 80 East Concord \\ Street, Boston, Masachusetts, USA \\ 2 Dipartimento di Biologia, Universita' di Roma 'Tor Vergata', Via della Ricerca \\ Scientifica, 00133 Roma, Italy \\ ${ }^{3}$ International Research Center for AIDS and other Emerging Infections, IRCCS \\ 'L. Spallanzani', Via Portuense 292, 00149, Rome, Italy \\ * corresponding author: Vittorio Colizzi, Dipartimento di Biologia, Universita' di \\ Roma 'Tor Vergata', Via della Ricerca Scientifica, 00133 Rome, Italy. \\ tel: ++39-6-72594235; fax: ++39-6-72594224; \\ e-mail: colizzi@utovrm.it
}

Received 31.3.98; revised 20.8.98; accepted 17.9.98

Edited by R.A. Knight

\begin{abstract}
Studies of host responses to infection have traditionally focused on the direct antimicrobial activity of effector molecules (antibodies, complement, defensins, reactive oxygen and nitrogen intermediates) and immunocytes (macrophages, lymphocytes, and neutrophils among others). The discovery of the systems for programmed cell death of eukaryotic cells has revealed a unique role for this process in the complex interplay between microorganisms and their cellular targets or responding immunocytes. In particular, cells of the monocyte/macrophage lineage have been demonstrated to undergo apoptosis following intracellular infection with certain pathogens that are otherwise capable of surviving within the hostile environment of the phagosome or which can escape the phagosome. Mycobacterium tuberculosis is a prototypical intracellular parasite' of macrophages, and the direct induction of macrophage apoptosis by this organism has recently been reported from several laboratories. This paper reviews the current understanding of the mechanism and regulation of macrophage apoptosis in response to $M$. tuberculosis and examines the role this process plays in protective immunity and microbial virulence.
\end{abstract}

Keywords: macrophage; apoptosis; tuberculosis; Mycobacterium tuberculosis

Abbreviations: MTB, Mycobacterium tuberculosis; AM $\Phi$, alveolar macrophage; TNF- $\alpha$, tumornecrosis factor- $\alpha$; TNFR, tumornecrosis factor receptor; CMI, cell-mediated immunity; DTH, delayed-type hypersensitivity; IFN- $\gamma$, interferon- $\gamma$; MDMФ, monocyte-derived macrophage; IL-1 $\beta$, interleukin-1 $\beta$; LPS, lipopolysaccharide; iNOS, inducible oxyde synthase; CTL, cytotoxic T cell; TUNEL, terminal transferase digoxygenin-dUTP nick end-labeling; IL-10, interleukin 10; BCG, Bacille Calmette-Guerin.

\section{Apoptosis in host defence}

Host responses to pathogenic microorganisms present a complex series of layered defenses. These include mucosal barriers, engulfment by non-antigenic-specific phagocytes, and ultimately specific immunity initiated by antigen-presenting cells (dendritic cells, macrophages, and B lymphocytes) and orchestrated by antigen-specific $T$ and $B$ lymphocytes through cytokine signaling, cytotoxic $T$ cell function, and antibody production. Clinical disease may occur both as a result of host cell destruction by invading pathogens, or as a consequence of the tissue destructive effects of the immune response. The traditional model of the host response to infection has focused on direct antimicrobial functions of immunocytes, but the discovery of programmed cell death has revealed a fascinating new aspect of the complex interaction between host and pathogen.

Apoptosis has been recognized as a component of protective host responses to virus infection for over a decade. ${ }^{1,2}$ When target cells are hijacked by these intracellular parasites, apoptosis limits resources available for viral replication and reduces the injurious consequences of cellular necrosis. The importance of this mechanism in the host response to virus infection is highlighted by the numerous anti-apoptotic genes which have evolved in many viral genomes. ${ }^{3}$ Certain bacterial and protozoan pathogens have evolved mechanisms to avoid elimination by cellular processes following phagocytosis, and these organisms are capable of survival and even replication within macrophages or other target cells. Infection by such intracellular pathogens presents the host with problem similar to that posed by viruses. It is not surprising then that apoptosis may also occur in this setting.

Target cell apoptosis in response to intracellular bacterial infection was first demonstrated with Shigella flexneri and Bordatella pertussis. ${ }^{4,5}$ In the following half-decade apoptosis has been identified in response to a growing number of bacterial and protozoan pathogens (Table 1). In most of these cases the cells manifesting this response are of monocyte-macrophage lineage. Induction of macrophage apoptosis is typically observed following in vitro or in vivo infection, although in some cases pathogens appear to inhibit host cell apoptosis, indicating that cell fate depends on a balance of both pro- and anti-apoptotic signals that may originate from the cell or the pathogen. ${ }^{6,7}$ This concept parallels the very complex interactions between cellular and viral effectors of cell death and survival. ${ }^{8-11}$

In the past decade the increasing incidence of clinically overt tuberculosis disease and the emergence of multi-drug resistance bacilli has stimulated clinical and basic research interest in this pathogen which is estimated to infect one third of the world's population. ${ }^{12}$ Among the new insights arising from this research, macrophage apoptosis has recently been identified in response to Mycobacterium tuberculosis (MTB) infection. This paper will review the data 
Table 1 Apoptosis and microbial pathogens

\begin{tabular}{|c|c|c|c|}
\hline Intracellular bacteria & Host cell & Apoptosis & Reference \\
\hline Shigella flexneri & Murine macrophage & Induction & 57 \\
\hline Bordetella pertussis & Murine macrophage & Induction & 4 \\
\hline \multirow[t]{2}{*}{ Listeria monocytogenes } & Murine hepatocyte and dendritic cell & Induction & 58 \\
\hline & Murine macrophage & Induction of necrosis & 59 \\
\hline Salmonella thyphimurium & Murine macrophage & Induction & 60 \\
\hline \multirow[t]{2}{*}{ Salmonella enterititidis } & Monocyte & Induction & 61 \\
\hline & & & 57 \\
\hline \multirow[t]{2}{*}{ Escherichia coli } & Monocyte & Induction & 61 \\
\hline & & & 62 \\
\hline Actinobacillus actinomycetemcomitans & Murine macrophage & Induction & 63 \\
\hline \multirow[t]{2}{*}{ Psuedomonas aeruginosa } & Human pro-monocyte & Induction & 61 \\
\hline & & & 64 \\
\hline Yersinia enterolitica & Murine macrophage & Induction & 65 \\
\hline \multirow[t]{2}{*}{ Staphylococcus aureus } & Ephitelial cell monocyte & Induction & 61 \\
\hline & & & 66 \\
\hline Legionella pneumophila & Human pro-monocyte & Induction & 67 \\
\hline Helicobacter pylori & Ephithelial & Induction & 68 \\
\hline \multirow[t]{4}{*}{ Mycobacterium tuberculosis } & Human monocyte/macrophage and & Induction or inhibition & 22 \\
\hline & alveolar macrophage & & 23 \\
\hline & & & 25 \\
\hline & Murine macrophage & & 29 \\
\hline \multirow[t]{2}{*}{ Mycobacterium bovis BCG } & Human monocyte & Induction or inhibition & 24 \\
\hline & & & 69 \\
\hline Leishmania donovani & Murine macrophage & Inhibition & 27 \\
\hline Toxoplasma gondii & Lymphoblast & $\begin{array}{l}\text { Inhibition of apoptosis } \\
\text { induced by other stimuli }\end{array}$ & 6 \\
\hline Chlamydia trachomatis & Epithelial Human pro-monocyte & $\begin{array}{l}\text { Inhibition of apoptosis } \\
\text { induced by other stimuli }\end{array}$ & 7 \\
\hline
\end{tabular}

describing this phenomenon and discuss the ways in which macrophage apoptosis might contribute to host defense against tuberculosis.

\section{Macrophages and the immune response to tuberculosis}

Tuberculosis infection is naturally acquired by inhalation. Those bacilli which manage to reach the alveolar compartment are phagocytosed by alveolar macrophages $(\mathrm{AM} \Phi)$. If phagocytosis is followed by killing the bacteria, then the infection is eliminated. The $А M \Phi$, however, may not necessarily mount an effective microbicidal response, permitting the establishment of persistent infection. Mycobacteria have evolved means to enhance their survival and replication within the macrophages by preventing maturation of the phagosomes which contain them. By inhibiting insertion of the membrane proton pump into its phagosome, mycobacteria prevent acidification of their intracellular environment. Furthermore, mycobacterial phagosomes can be restricted from fusing with the lysosomal compartment. In this way, intracellular bacilli are protected from potent host antimicrobial effector processes. Instead of functioning normally to kill internalized bacilli, the macrophage provides an environment suitable for bacterial replication. ${ }^{13,14}$ Survival within the AM $\Phi$ may also serve to protect bacilli from other more effective host response mechanisms, and is likely to play a role in latency and persistence of tuberculosis infection. Latency is a characteristic feature of tuberculosis; in immunocompetent adults the initial infection and systemic dissemination are usually arrested without the development of clinical disease. In approximately $10 \%$ of infected individuals, dormant bacilli (believed to be located within macrophages) reactivate months or years later, resulting in clinically active tuberculosis. Thus, M. tuberculosis is a prototypical 'intracellular parasite' of macrophages and it is reasonable to postulate that defense mechanisms specific to intracellular pathogens may be an important component of host defense in tuberculosis.

If $M$. tuberculosis survives its initial encounter with the $\mathrm{AM}$, a granulomatous response may follow with the development of localized collections of epithelioid giant cells, macrophages, newly recruited monocytes, and lymphocytes. This reaction is antigen-independent and can be elicited experimentally by a variety of simple stimuli including systemic injection of mycobacterial cord factor. ${ }^{15}$ Macrophage-pathogen interactions within the developing granuloma directly stimulate the release of several cytokines that have been linked to protection in animal models. Among them, tumor necrosis factor- $\alpha$ (TNF- $\alpha$ ) is thought to play an important role and its expression in tuberculous granulomas has been directly demonstrated. ${ }^{16}$ Antibody neutralization experiments, and studies of mice with targeted deletion of the TNF receptor p55 (TNFR1; 17) indicate that TNF- $\alpha$ is required for protection of the host. In the absence of TNF-R1, survival was dramatically reduced following infection with virulent $M$. tuberculosis and while granulomas formed in these animals, they contained more bacilli than controls and epithelioid cells were absent. Finally, there was more prominent lung tissue necrosis in the TNF-R1 deficient animals which has important 
implications for the pathobiology of tuberculosis and disease transmission (vide infra).

While the granuloma provides a significant barrier to further spread of infection, infectious bacilli are not reliably eradicated by this response. Definitive antigen-specific host responses to tuberculosis include cell-mediated immunity (CMI) in which $M$. tuberculosis-reactive $\mathrm{T}$ cells activate macrophages to enhance killing of intracellular bacilli, and delayed-type hypersensitivity (DTH) characterized at the systemic level by tuberculin skin test reactivity and at the

A

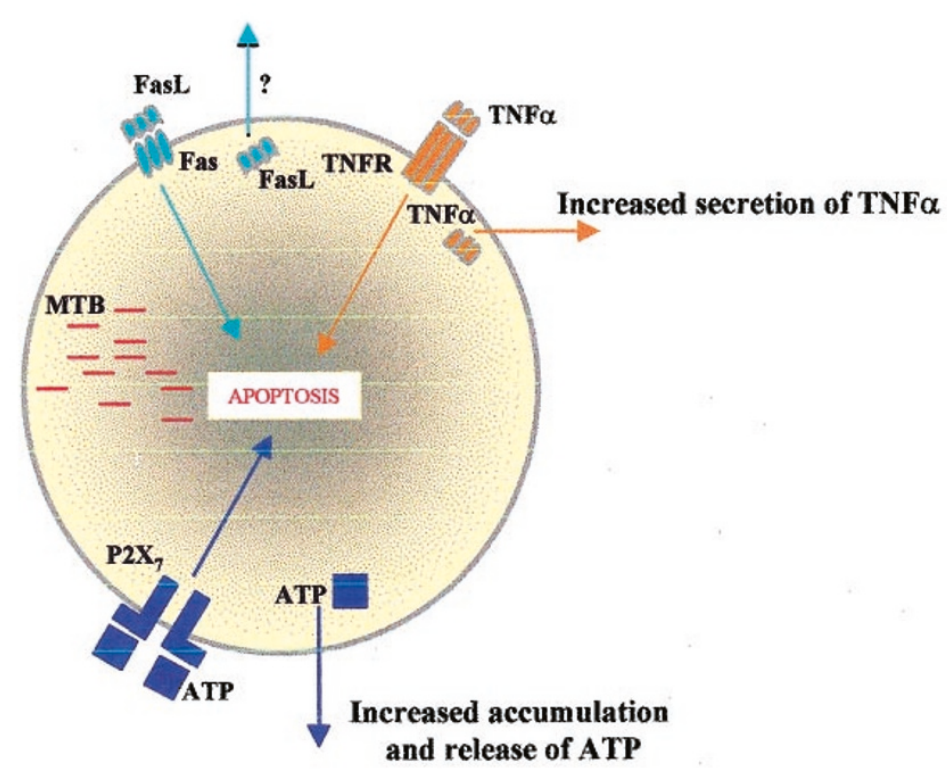

B

No MTB-killing

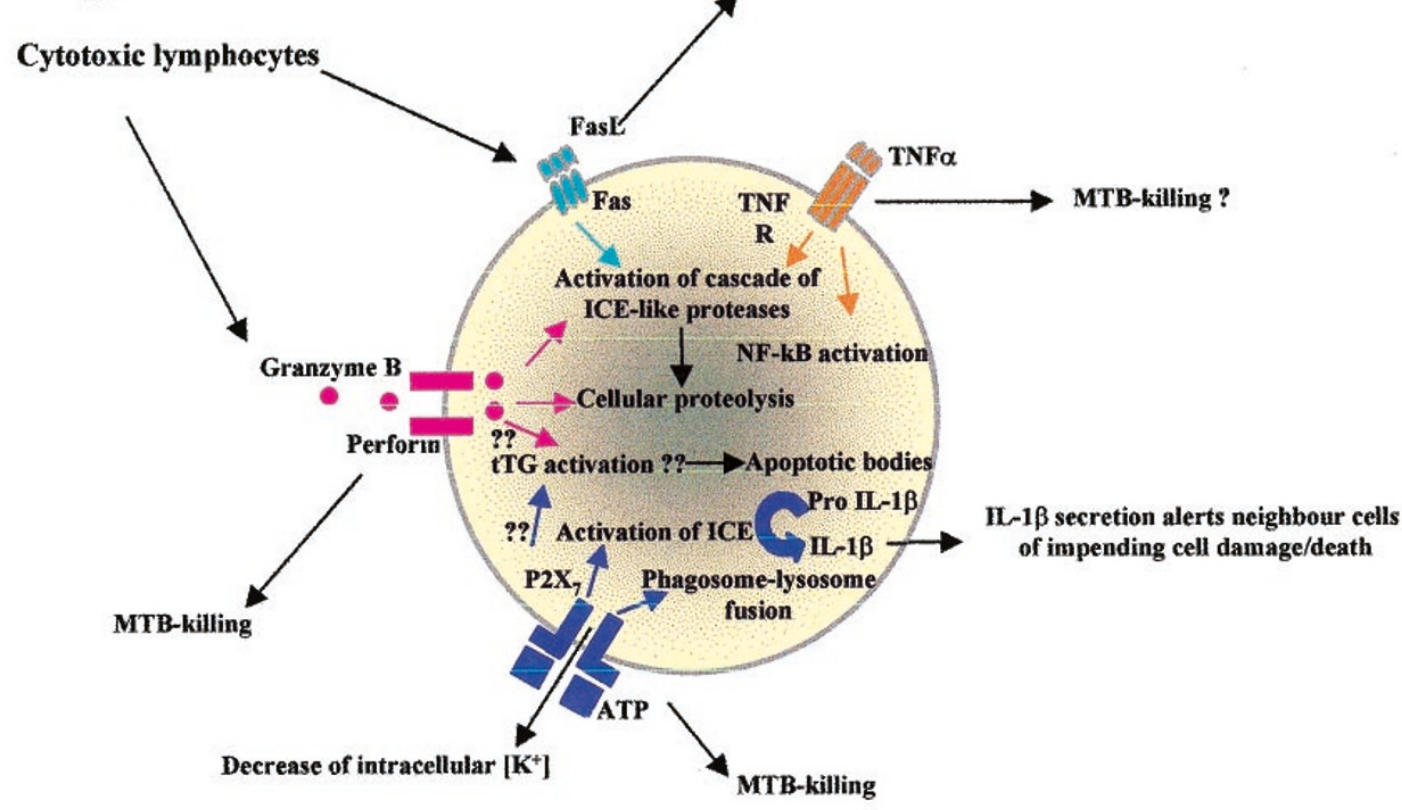

Figure 1 (A) Model for autocrine-paracrine induction of apoptosis by different pathways during infection of monocytes/macrophages by Mycobacterium tuberculosis. (B) Molecular mechanisms in the apoptosis of Mycobacterium tuberculosis infected-human macrophages. Activation of purinergic receptors by extracellular ATP and granule-dependent cytotoxicity was reported to be an effective mechanism for mycobacteria killing. On the contrary cytotoxicity of T cells mediated by Fas-FasL interaction had no effect on the viability of mycobacteria, while CD8+ T cells that lyse macrophages by granule dependent Fas-independent mechanism result in killing of the intracellular pathogen 
local level by $\mathrm{T}$ cell-mediated killing of bacilli-laden macrophages. ${ }^{18,19}$ It has been proposed that effective $\mathrm{CMI}$ contains infection with minimal tissue injury to the host, while DTH produces a more tissue-damaging response. ${ }^{20}$ Macrophage activation in $\mathrm{CMI}$ is believed to be chiefly mediated by interferon- $\gamma($ IFN- $\gamma$ ) released from activated lymphocytes, although $A M \Phi$ themselves have recently been reported to produce and respond to endogenous IFN- $\gamma$ following stimulation with $M$. tuberculosis. ${ }^{21}$ In approximately $10 \%$ of infected individuals these antigen-specific responses are ultimately unable to control the infection. After a rather variable period of latency, progressive local pulmonary disease develops which is characterized by tissue destruction and cavity formation. Since man is the definitive host, lung tissue destruction is critical for the perpetuation of $M$. tuberculosis. Only by producing a necrotic infection with connection to the airway can infectious aerosols be produced enabling transmission of the microorganism to its next host.

\section{Macrophage apoptosis in response to $M$. tuberculosis infection in vitro}

Recent reports from several laboratories provide evidence that apoptosis is triggered by $M$. tuberculosis interaction with monocytes and macrophages including its definitive host cell, the AMФ. Keane et al. ${ }^{22}$ inoculated primary human $\mathrm{AM} \Phi$ with M. tuberculosis strains $\mathrm{H} 37 \mathrm{Rv}$ (virulent in mice) or H37Ra (attenuated). Macrophage apoptosis was observed with both strains, although H37Ra was a more potent inducer than H37Rv. This apoptosis was blocked by inhibition of endogenous TNF- $\alpha$ and accelerated by the addition of exogenous TNF- $\alpha$, while the viability of uninfected macrophages was not affected by TNF- $\alpha$. These data indicate that M. tuberculosis challenge in some way sensitizes $A M \Phi$ to autocrine and/or paracrine TNF $\alpha$-mediated apoptosis. Apoptosis of primary human monocyte-derived macrophages (MDMФ) following exposure of $M$. tuberculosis H37Rv in vitro was reported by Placido et $a l^{23}$ and Klingler et $a^{R^{4}}$ noted a similar response to H37Ra. The data of Placido and Keane both indicate that apoptosis requires challenge with live mycobacteria; heat-killed organisms had no effect on macrophage viability. This suggests that the signal which primes macrophages for apoptosis is generated from within the cell, rather than resulting from activation of cell surface receptors engaged by the bacteria.

The apoptotic response to mycobacteria may be restricted to mature macrophages. Durrbaum-Landmann et $a^{25}$ found that human monocytes isolated by counterflow centrifugation undergo spontaneous apoptosis over time in culture under unstimulated conditions. Apoptosis was reduced when monocytes were cultured with low numbers of H37Rv or with zymosan, but not latex beads. This result is consistent with earlier reports that monocytes undergo spontaneous apoptosis in the absence of growth factors, but can be rescued by activating agents including TNF- $\alpha$, interleukin-1 $\beta$ (IL-1 $\beta)$, and bacterial lipopolysaccharide (LPS), ${ }^{26}$ as well as by infection with $L$. donovani. ${ }^{27}$ In contrast, differentiated macrophages lose their sensitivity to growth factor withdrawal but are susceptible to activation- induced apoptosis. ${ }^{28}$ The regulation of programmed cell death in terminally differentiated, non-dividing, macrophages is clearly distinct from that of their cycling precursors. This distinction has important implications for the design of in vitro infection-induced apoptosis experiments using transformed cell lines or blood monocytes.

Apoptosis of murine macrophages following in vitro challenge with $M$. tuberculosis has also been identified. Rojas et $a^{29}$ tested murine macrophage cell lines congenic at the $B c g /$ Nramp 1 gene, finding that B10R cells were more prone to apoptosis than B10S cells following exposure to live M. tuberculosis H37Rv. In contrast to primary human $\mathrm{AM} \Phi, \mathrm{H} 37 \mathrm{Ra}$ did not stimulate apoptosis of the B10R cells in these studies. A role for $\mathrm{NO}^{-}$and inducible nitric oxide synthase (iNOS) in B10 cell apoptosis was shown in experiments with aminoguanidine and nitroprusside, whereas human $\mathrm{AM} \Phi$ apoptosis was previously found not to be affected by iNOS inhibitors. ${ }^{22}$ However, apoptosis of B10R and B10S cells was inhibited by anti-TNF- $\alpha$ antibody, suggesting that the apoptotic mechanism for murine cells shares some similarities with the human macrophage response to mycobacterial infection. Of interest, treatment with mannose-capped lipoarabinomannan or LPS rescued murine B10R and B10S cells from apoptosis despite inducing $\mathrm{NO}^{-}$production. While it is not certain that the responses of primary murine macrophages will be faithfully mirrored by tumor cell lines, these data suggest that apoptosis in response to intracellular infection by $M$. tuberculosis is common to both man and mouse. This is supported by induction of apoptosis in primary murine $А М \Phi$ by $M$. tuberculosis infection in vitro (J. Keane, unpublished observations).

\section{Death signaling pathways in M. tuberculosis-infected macrophages}

The data of Keane et $a^{R^{2}}$ indicate that TNF- $\alpha$ is a major initiator of apoptotic signaling for macrophages harboring intracellular mycobacteria. Infected macrophages become primed for killing by TNF- $\alpha$, whereas uninfected macrophages are resistant to this effect. Several studies have noted that intracellular infection by $M$. tuberculosis and certain other intracellular bacteria can sensitize various cell types to TNF- $\alpha$ mediated death ${ }^{30-32}$ This suggests the existence of a common mechanism for the detection of viable intracellular bacilli that triggers a 'danger signal', priming the cell for elimination by TNF- $\alpha$ a cytokine that is almost universally induced by macrophage-pathogen interactions. The nature of this priming signal, whether it is of bacterial or cellular origin is a matter of speculation at this time. It is also unknown if this sensitization process occurs as a result of differential expression of TNFR1, or some downstream mechanism. Since TNFR1 mediates three different signaling pathways by differential association with various intracellular adaptor proteins (apoptosis via FADD, JNK activation, and NF- $\kappa \mathrm{B}$ translocation; ${ }^{33}$ ) a number of control points are possible.

It is possible that simple engagement of cell surface receptors by mycobacterial cell wall components could suffice to trigger sensitization to TNF- $\alpha$-mediated cell death, but this is unlikely since heat-killed $M$. tuberculosis has 
been shown not to induce apoptosis. ${ }^{22,23}$ Although extracellular signaling by LPS can induce AMФ apopto$\mathrm{sis}^{34}$ the mechanism appears to be unrelated to that of mycobacterial infection. Apoptosis induced by LPS was unaffected by TNF- $\alpha$ but was accelerated by IFN- $\gamma$, whereas apoptosis induced by $M$. tuberculosis is accelerated by TNF- $\alpha$ but is not enhanced by IFN- $\gamma^{22}$ (and unpublished observations). Hayashi et $a^{\beta 5}$ reported that a sonicate of $M$. avium could induce apoptosis of human MDM $\Phi$ at concentrations of $300 \mu \mathrm{g} / \mathrm{ml}$ or greater, however, indicating that the potential for extracellular signals from mycobacteria to mediate cell death bears further investigation.

Death signaling receptor pathways other than TNF-R1 may also play a role in $M$. tuberculosis-induced macrophage apoptosis. The P2X purinergic receptor family are plasma membrane ligand-gated ion channels activated by ATP that are structurally related to Caenorhabditis elegans degenerin channels and to mammalian epithelial amiloridesensitive sodium channels. ${ }^{36}$ Mononuclear phagocytes express $\mathrm{P}_{2} \mathrm{X}_{7}$ whose activation causes apoptosis in human MDM $\Phi$ and mouse microglial cells. ${ }^{37,38}$ Recent data show that $M$. tuberculosis-infected MDM $\Phi$ increase the expression of $\mathrm{P}_{2} \mathrm{X}_{7}$ receptors and that ATP accumulates and is released from these cells in the early phase of infection; this suggests an alternative autocrine/paracrine mechanism for the direct induction of macrophage apoptosis in response to infection (Mancino et al, unpublished observations).

Involvement of Fas in the macrophage death response to $M$. tuberculosis also bears consideration. Human MDM $\Phi$ have constitutive expression of Fas and undergo apoptosis if treated with soluble recombinant FasL. ${ }^{39}$ However, Fas expression was down regulated by $M$. tuberculosis infection and there is no evidence that resting or infected MDMФ express FasL. Thus, Fas-mediated death signaling may not play a role in the direct induction of apoptosis of infected macrophages prior to the recruitment of $T$ cells to the lung when infection is controlled primarily by the innate immune activity of macrophages. In contrast, both Fas and purinergic receptor stimulation may be involved in cytotoxic $\mathrm{T}$ cell (CTL)-mediated killing of infected macrophages.

The fate of $M$. tuberculosis-infected macrophages may be determined not only by death signaling pathway activation, but also by the activity of downstream regulators of apoptosis. Evidence that nuclear translocation of NF- $\kappa$ B protects against TNF- $\alpha$-mediated apopto$\mathrm{sis}^{40,41}$ suggests a mechanism for regulating the apoptotic response of infected cells. Macrophage activation by $M$. tuberculosis activates a variety of signaling pathways, including NF- $\kappa \mathrm{B} ;{ }^{42}$ elevated levels of nuclear NF- $\kappa \mathrm{B}$ would be expected to protect cells from infection-induced apoptosis while reduced levels would promote cell death. In this regard, a non-apoptosis-inducing mycobacterium ( $M$. smegmatis) was recently found to cause apoptosis of target macrophages pre-treated with the proteasome inhibitor lactacystin $(\mathrm{H}$. Remold, personal communication). The $\mathrm{bcl}-$ 2 gene family encodes dominant regulators of apoptotic cell death $^{43,44}$ that could also play a role in tuberculosisinduced apoptosis. Down-regulation of $\mathrm{Bcl}-2$ protein expression was proposed by Klingler et $a^{24}$ as a factor regulating apoptosis of infected macrophages. They reported downregulation of $\mathrm{Bcl}-2$ protein, but not $\mathrm{Bax}$, following infection with Bacille Calmette-Guerin (BCG) or exposure to heat-killed $M$. tuberculosis H37Ra. The outcome of mycobacterial binding and phagocytosis might hinge on the relative strength or duration of pro- and antiapoptotic signals affecting the relative levels of nuclear NF$\kappa \mathrm{B}$ activity as well as the intracytoplasmic ratio of $\mathrm{Bcl}-2$ to Bax.

\section{Macrophage apoptosis in tuberculosis in vivo}

Macrophage apoptosis in response to mycobacterial infection would be of limited interest if it were only a phenomenon of in vitro culture. Several lines of evidence, however, indicate that apoptosis is a common event in tuberculosis infection in vivo, and that a significant proportion of macrophages at sites of granulomatous inflammation are susceptible. Placido et $a^{23}$ identified increased numbers of apoptotic $А М \Phi$ in bronchoalveolar lavage of tuberculosis patients, and even greater numbers in patients dually infected tuberculosis and HIV-1. This finding was confirmed by Klinger et $a^{R^{4}}$ in bronchoalveolar lavage studies comparing cells obtained from involved sites of the lung in patients with pulmonary tuberculosis to cells from uninvolved lobes of the lung in these same patients, and to normal control. Using in situ terminal transferase digoxygenin-dUTP nick end-labeling (TUNEL) the proportion of apoptotic cells was $14.8 \pm 1.9 \%, 4.3 \pm 0.9 \%$, and $<1 \%$ in these three groups, respectively. An early light microscopic survey of tuberculous granulomas reported the infrequent occurrence of cells with morphologic changes consistent with apoptosis. ${ }^{45}$ Using the more sensitive in situ TUNEL method, Keane et $a^{R^{2}}$ examined lung sections from clinical cases of tuberculosis and estimated that $>50 \%$ of cells in the periphery of granulomas were positive. Furthermore, Mancino et al (unpublished observations) found that in similar sections, typical tuberculous granulomata characterized by a core of caseous necrosis containing dying cells were surrounded by a cuff of apoptotic МФ. The demonstration of increased TNF- $\alpha$ expression in these lesions ${ }^{16}$ is consistent with its proposed role in macrophage apoptosis. The direct induction of macrophage apoptosis by $M$. tuberculosis is certainly only one of several pathways responsible for the TUNEL-positive cells demonstrated in clinical specimens. These tissues are virtually always obtained from patients with fully developed tuberculosis where the effects of CMI and DTH are also evident.

\section{Host defense functions of macrophage apoptosis}

While the evidence that apoptosis is a prominent macrophage response to tuberculosis infection is strong, it is much less clear what role it plays in the pathobiology of disease. It may be hypothesized that macrophage apoptosis benefits the infecting bacillus by depriving the host of an effective phagocyte without amplifying local inflammation that might be detrimental to bacterial survival. In this model, efficient 
elimination of $A M \Phi$ by a mechanism that limits inflammation might interrupt or at least delay the induction of antigenspecific CMI and DTH responses. This hypothesis deserves testing, but an opposing model where macrophage apoptosis is predicted to benefit the host fits the pattern of responses to intracellular infection established for many other intracellular pathogens and provides a more satisfying explanation of the available data. The enhanced susceptibility to mycobacteriainduced apoptosis of murine B10R macrophages (derived from mice resistant to BCG), compared to B10S cells (from susceptible mice) supports a linkage between macrophage apoptosis and protection. ${ }^{29}$ This hypothesis is further supported by the observation that the attenuated mycobacterial strains (e.g. H37Ra and BCG) are significantly more potent inducers of apoptosis than virulent strains such as H37Rv, Erdman, and wild type $M$. bovis ${ }^{22}$ (and unpublished observations). Just as certain viruses produce anti-apoptotic factors, H37Rv was found to induce the shedding of soluble TNF-R2 (sTNF-R2) from infected AM $\Phi$ which inhibited the TNF- $\alpha$ death signal accounting, at least in part, for the reduced apoptosis caused by this strain as compared with H37Ra. ${ }^{46}$

Although $M$. tuberculosis growth may be inhibited after phagocytosis by $\mathrm{AM} \Phi,{ }^{47}$ a microbicidal effect has not been demonstrated in vitro and it is clear that the bacillus continues to be matabolically active and may replicate within its phagosome. ${ }^{48-50}$ Reports from several investigators indicate that apoptosis of infected macrophages, but not lysis, may effectively limit mycobacterial growth. Molloy et $a^{{ }^{1}}$ infected $\mathrm{MDM} \Phi$ with $\mathrm{BCG}$ and subsequently treated the cells with either $\mathrm{H}_{2} \mathrm{O}_{2}$ to induce lysis or ATP to induce apoptosis. The viability of BCG was reduced only following treatment with ATP. These data were recently confirmed using MDM $\Phi$ infected with M. tuberculosis H37Rv (Mancino et al, unpublished observations). Induction of apoptosis of MTB-infected MDM $\Phi$ by pulsing with extracellular ATP enhanced the killing of intracellular mycobacteria, demonstrating a pivotal role of these receptors in the host defense against intracellular infection. The mechanism of bacterial growth inhibition by purinergic receptor activation is unknown, but effects on phagosome/lysosome fusion and vacuolar $\mathrm{pH}$ have been suggested, ${ }^{51,52}$ (and Mancino et al. unpublished observations). Similarly, Oddo et $a^{\beta 9}$ demonstrated a reduction in mycobacterial viability when infected macrophages were stimulated with rsFasL. In contrast, Fas activation was found to have no effect on $M$. avium viability ${ }^{53}$ while Stenger et al. ${ }^{19}$ showed that $\mathrm{CD} 1$-restricted $\mathrm{CD}^{-}{ }^{-} \mathrm{CR} 8^{-}$cytotoxic $\mathrm{T}$ cells killed infected macrophages by a Fas-FasL interaction without killing the mycobacteria, whereas $\mathrm{CD}^{+} \mathrm{CTL}$ killed target cells by a granule-dependent process which resulted in killing bacteria. These contrasting results, possibly explained by the very different experimental systems employed, leave open the question whether Fas-mediated apoptosis provides an antimicrobial effect similar to apoptosis induced by ATP.

In addition to any direct antimicrobial function of macrophage apoptosis, this process will significantly alter the interaction of infected macrophages with other host defense cells. Monocytes are actively recruited to sites of tuberculosis-induced inflammation in vivo, ${ }^{54}$ where they may encounter $M$. tuberculosis-infected $A M \Phi$ undergoing apoptosis as well as bacilli contained in apoptotic bodies. The work of Fratazzi et $a^{55}$ indicate that mycobacteria presented to macrophages within apoptotic bodies may be handled differently than free bacilli, resulting in more potent suppression of bacterial growth. In these experiments, fresh uninfected autologous MDM $\Phi$ were added to cultures of MDM $\Phi$ previously innoculated with $M$. avium and undergoing apoptosis due to the mycobacterial infection. Uninfected macrophages were seen to adhere to the infected, apoptotic, cells and a reduction in bacterial growth of $>90 \%$ was observed. In contrast, fresh MDMФ added to cultures of infected MDM $\Phi$ which had undergone lysis failed to restrict bacterial growth. This result suggests that phagocytosis of bacilli packaged within apoptotic bodies might lead directly to lysosomal fusion, circumventing the interruption of phagosomal maturation seen when free $M$. tuberculosis bacilli are internalized.

In addition to limiting bacterial replication, macrophage apoptosis might also serve to limit tissue destruction in tuberculosis. If an orderly process of apoptosis predominates over cell lysis and tissue destruction, ${ }^{56}$ the architecture of the lung will be preserved and the spread of infection to new hosts will be prevented. Man is the definitive host for $M$. tuberculosis and perpetuation of the bacteria requires it to establish a connection to the bronchial tree for aerosol transmission. In this regard, the lungs of mice with targeted deletion of TNF-R1 showed areas of necrosis in addition to granulomas following $M$. tuberculosis infection, whereas control mice had only granulomas without evidence of lung necrosis. In untreated human tuberculosis mortality and morbidity primarily result from lung damage and the residual pulmonary scarring following clinical tuberculosis contrast dramatically with minimal residual damage after even severe pneumonia due to routeine pathogens such as Streptococcus pneumoniae.

\section{Conclusions}

Alveolar macrophage apoptosis has now been demonstrated to be a common response to intracellular infection by $M$. tuberculosis both in vitro and in vivo. Experimental evidence supports a prominent role for TNF- $\alpha$ in this process; other death signaling receptor pathways such as $\mathrm{P}_{2} \mathrm{X}_{7}$ and Fas may also participate. Host-protective functions for this response are likely to include the elimination of a protected intracellular environment conducive to bacterial replication or suitable for bacterial latency, as well as direct and indirect microbicidal actions. The former have been demonstrated experimentally but the mechanism for mycobacterial killing during apoptosis of infected macrophages is unknown. Experimental evidence suggests that indirect effects on mycobacterial replication are due to more effective handling of bacilli taken up when uninfected macrophages phagocytose apoptotic cells and debris. Additional roles for macrophage apoptosis in sparing tissue damage and signaling for monocyte and lymphocyte recruitment and activation are speculative but merit investigation. 
It has been clearly demonstrated that not all strains of $M$. tuberculosis and related mycobacteria are equally potent inducers of macrophage apoptosis. Preliminary data indicate that in vitro infection with more virulent organisms results in significantly less macrophage cell death. The apparent inverse correlation between virulence and apoptosis is consistent with the more well understood relationship between viruses and their host cells where virus-encoded genes act to suppress the protective host cell apoptotic response. In the context of tuberculosis, this represents a new virulence associated phenotype whose mechanistic basis remains to be defined. Data indicate that in one example (H37Rv), the bacteria triggers a macrophage response (IL-10 production) that ultimately leads to inhibition of cell killing by TNF- $\alpha$, but other mechanisms to either avoid triggering, or otherwise suppress, the apoptotic response may be identified as additional virulent strains are tested.

Macrophage apoptosis in response to tuberculosis infection has only recently been appreciated, and its implications for in vitro experimentation and for the pathobiology of tuberculosis disease remain to be explored. The choice of target cells for such experiments must be carefully considered since the available data indicate that primary monocytes, $M D M \Phi$ and $A M \Phi$, and monocytic tumor cell lines, do not necessarily exhibit identical activities. While in vitro studies may provide new mechanistic insights, they will not be sufficient to determine how macrophage apoptosis functions in the context of the systemic host response to tuberculosis. Animal models are likely to contribute in this arena, but differences in immunology and pathology of human and murine tuberculosis must be considered in the interpretation of any result. An important first step will be to more completely define the similarities and differences in the response of primary murine and human macrophages to $M$. tuberculosis infection in vitro.

\section{Acknowledgements}

This work was supported in part by Insituto Superiore di Sanità (ISS)Progetto di Ricerca Tubercolosi. G.M. wishes to thank the ISS for financial support. Special thanks are due to Dr. Palma Mattioli for the image analysis, and to Dr. Franco Nasella for the invaluable help in literature research.

\section{References}

1. Clem RJ and Miller LK (1993) Apoptosis reduces both the in vitro replication and the in vivo infectivity of a baculovirus. J. Virol. 67: 3730-3738

2. Clouston WM and Kerr JF (1985) Apoptosis, lymphocytotoxicity and the containment of viral infections. Medical Hypotheses 18: 399-404

3. Vaux DL and Strasser A (1996) The molecular biology of apoptosis. Proc. Natl. Acad. Sci. USA. 93: 2239-2244

4. Khelef N, Zychlinsky A and Guiso N (1993) Bordatella pertussis induces apoptosis in macrophages: role of adenylate cyclase-hemolysin. Infect. Immun. 61: $4064-4070$

5. Zychlinsky A, Prevost MC and Sansonetti PJ (1992) Shigella flexneri induces apoptosis in infected macrophages. Nature 358: 167-169

6. Nash PB, Purner MB, Leon RP, Clarke P, Duke RC and Curiel TJ (1998) Toxoplasma gondii-infected cells are resistant to multiple inducers of apoptosis. J. Immunol 160: $1824-1830$
7. Fan T, Lu H, Hu H, Shi L, McClarty GA, Nance DM, Greenberg AH and Zhong G (1998) Inhibition of apoptosis in Chlamydia-infected cells: blockade of mitochondrial cytochrome $c$ release and caspase activation. J. Exp. Med. 187: 487-496

8. Clem RJ, Fechheimer M and Miller LK (1991) Prevention of apoptosis by a baculovirus gene during infection of insect cells. Science 254: 13881390

9. Ray CA, Black RA, Kronheim SR, Greenstreet TA, Sleath PR, Salvesen GS and Pickup DJ (1992) Viral inhibition of inflammation: cowpox virus encodes an inhibitor of the interleukin-1 beta converting enzyme. Cell 69: $597-604$

10. Sieg S, King C, Huang Y and Kaplan D (1996) The role of interleukin-10 in the inhibition of T-cell proliferation and apoptosis mediated by parainfluenza virus type 3. J. Virol. 70: $4845-4848$

11. Thome M, Schneider P, Hofmann K, Fickenscher H, Meinl E, Neipel F, Mattman C, Burns K, Bodmer JL, Schroter M, Scaffidi C, Krammer PH, Peter ME and Tschopp J (1997) Viral FLICE-inhibitory proteins (FLIPs) prevent apoptosis induced by death receptors. Nature 386: $517-521$

12. Bloom BR and Murray CJL (1997) Tuberculosis: commentary on a reemergent killer. Science 257: 1055-1064

13. RusselDG(1995) Of microbes and macrophages: entry, survival and peristence. Current Opinion Immunol. 7: 479-483

14. Sturgill-Koszycki S, Schlesinger PH, Chakraborty P, Haddix PL, Collins HL, Fok AK, Allen RD, Gluck SL, Heuser J and Russell DG (1994) Lack of acidification in Mycobacterium phagosomes produced by exclusion of the vescicular protonATPase. Science 263: 678-680

15. Ozeki Y, Kaneda K, Fujiawara N, Morimoto M, Oka S and Yano I (1997) In vivo induction of apoptosis in the thymus by administration of mycobacterial cord factor (trehalose 6,6'-dimycolate). Infect. Immun. 65: 1793-1799

16. Myatt N, Coghill G, Morrison K, Jone D and Cree IA (1994) Detection of tumor necrosis factor $\alpha$ in sarcoidosis and tuberculosis granulomas using in situ hybridisation. J. Clin. Pathol. 47: 423-426.

17. Flynn JL, Goldstein MM, Chan J, Triebold KJ, Pfeffer K, Lowenstein CJ, SchreiberR, Mak TW and Bloom BR (1995) Tumornecrosis factor- $\alpha$ is required in the protective immune response against Mycobacterium tuberculosis in mice. Immunity 2: $561-572$

18. Kumararatne DS, Pithie AS, Drysdale P, Gaston JSH, Kiessling R, Iles PB, Ellis CJ, Innes J and Wise R (1990) Specific lysis of mycobacterial antigen-bearing macrophages by class II MHC-restricted polyclonal T cell lines in healthy donors or patients with tuberculosis. Clin. Exp. Immunol. 80: 314-323

19. Stenger S, Mazzaccaro RJ, Uyemura K, Cho S, Barnes PF, Rosat JP, Sette A, Brenner MB, Porcelli SA, Bloom BR and Modlin RL (1997) Differential effects of cytolytic $T$ cell subsets on intracellular infection. Science 276: $1684-1687$

20. Dannenberg AM and Rook GAW (1994) Pathogenesis of pulmonary tuberculosis: an interplay of tissue-damaging and macrophage-activating responses-Dual mechanisms that control bacillary multiplication. In: Tuberculosis: Pathogenesis, Protection, and Control. B.R. Bloom, (ed.) American Society for Microbiology, Washington, D.C., pp. 459-483

21. Fenton MJ, Vermeulen MW, Kim S, Burdick M, StrieterRMand Kornfeld H (1997) Induction of gamma interferon production in human alveolar macrophages by Mycobacterium tuberculosis. Infect. Immun. 65: 5149-5156

22. Keane J, Balcewicz-Sablinska K, Remold HG, Chupp GL, Meek BB, Fenton MJ and Kornfeld $H$ (1997) Infection by Mycobacterium tuberculosis promotes human elveolar macrophage apoptosis. Infect. Immun. 65: 298-304

23. Placido R, Mancino G, Amendola A, Mariani F, Vendetti S, Piacentini M, Sanduzzu A, Bocchino ML, Zembala M and Colizzi V (1997) Apoptosis of human monocytes/macrophages in Mycobacterium tuberculosis infection. J. Pathol. 181: $31-38$

24. Klingler K, Tchou-Wong KM, Brandli O, Aston C, Kim R, Chi C and Rom WN (1997) Effects of mycobacteria on regulation of apoptosis in mononuclear phagocytes. Infect. Immun. 65: 5272-5278

25. Durrbaum-Landmann I, Gercken J, Flad HD and Ernst M (1996) Effect of an in vitro infection of human monocytes with low numbers of Mycobacterium tuberculosis bacteria on monocyte apoptosis. Infect. Immun. 64: 5384-5389

26. Managan DF, Welch GR and Wahl SM (1991) Lipopolysaccharide, tumor necrosis factor-alpha, and IL-1 beta prevent programmed cell death (apoptosis) in human peripheral blood monocytes. J. Immunol. 146: 1541-1546

27. Moore KJ and Matlashewski G (1994) Intracellular infection by Leishmania donovani inhibits macrophage apoptosis. J. Immunol. 152: 2930-2937 
28. Munn DH, Beall AC, Song D, Wrenn RW and Throckmorton DC (1995) Activation-induced apoptosis in human macrophages: developmental regulation of a novel cell death pathway by macrophage colony-stimulating factor and interferon gamma. J. Exp. Med. 181: 127-136

29. Rojas M, Barrera LF, Puzo G and Garcia LF (1997) Differential induction of apoptosis by virulent Mycobacterium tuberculosis in resistant and susceptible murine macrophages. J. Immunol. 159: 1352-1361

30. Filley EA, Bull HA, Dowd PM and Rook GAW (1992) The effect of Mycobacterium tuberculosis on the susceptibility of human cells to the stimulatory and toxic effects of tumour necrosis factor. Immunology 77: 505-509

31. Filley EA and Rook GA (1991) Effect of mycobacteria on sensitivity to the cytotoxic effects of tumor necrosis factor. Infect. Immun. 59: 2567-2572

32. Klimpel GR, Shaban R and Niesel DW (1990) Bacteria-infected fibroblasts have enhanced susceptibility to the cytotoxic action of tumor necrosis factor. J. Immunol. 145: 711-717

33. Liu Z, Hsu H, Goeddel DV and Karin M (1996) Dissection of TNF receptor 1 effector functions: JNK activation is not linked to apoptosis while NF- $k \mathrm{~B}$ activation prevents cell death. Cell 87: 565-576

34. Bingisser R, Stey C, Weller M, Groscurth P, Russi E and Frei K (1996) Apoptosis in human alveolar macrophages is induced by endotoxin and is modulated by cytokines. Am. J. Respir. Cell Mol. Biol. 15: 64-70

35. Hayashi T, Catanzaro A and Rao SP (1997) Apoptosis of human monocytes and macrophages by Mycobacterium avium sonicate. Infect. Immun. 65: 52625271

36. North RA (1996) Families of ion channels with two hydrophobic segments. Curr. Opin. Cell. Biol. 8: 474-483

37. Di Virgilio F (1995) The P2Z purinoreceptors: an intriguing role in immunity, inflammation and cell death. Immunol. Today 16: 524

38. Ferrari D, Chiozzi P, Falzoni S, Hanau S and Di Virgilio F (1997). Purinergic modulation of interleukin- $1 \beta$ release from microglial cells stimulated with bacterial toxin. J. Exp. Med. 185: 579-582

39. Oddo M, Reno T, Attinger A, BakkerT, Macdonal HR and Meylan PAR (1998) Fas ligand-induced apoptosis of infected human alveolar macrophages reduces the viability of intracellular Mycobacterium tuberculosis. J. Immunol. 160: 5448 5454

40. Begg AA and Baltimore D (1996) An essential role forNF- $k$ B in preventing TNF- $\alpha-$ induced cell death. Science 274: 782-784

41. Wang CY, Mayo MW and Baldwin Jr AS (1996)TNF-and cancertherapy-induced apoptosis: Potentiation by inhibition of NF- $\kappa$ B. Science 274: 784-789

42. Toosi Z, Hamilton BD, Phillips MH, Averill LE, Ellner JJ and Salvekar A (1997) Regulation of nuclear factor-kappa B and its inhibitor I kappa B-alpha/MAD-3 in monocytes by Mycobacterium tuberculosis and during human tuberculosis. $\mathrm{J}$. Immunol. 159: 4109-4116

43. Boise LH, Gonzalez-Garcia M, Postema CE, Ding L, Lindsten T, Turka LA, Mao X, Nunez $\mathrm{G}$ and Thompson CB (1993) $b c l-x$, a $b c l-2$-related gene that functions as a dominant regulator of apoptotic cell death. Cell 74: 597-608

44. Oltavi ZN, Millman CL and Korsmeyer SJ (1993) Bcl-2 heterodimerizes in vivo with a conserved homolog, Bax, that accelerates programmed cell death. Cell 74: $609-619$

45. Cree IA, Nurbhai S, Milne G and Beck JS (1995) Cell death in granulomata: the role of apoptosis. J. Clin. Pathol. 40: 1314-1319

46. Balcewicz-Sablinska MK, Keane J, Kornfeld H and Remold H (1998) Mycobacterium tuberculosis suppresses TNF- $\alpha$ induced programmed cell death in the host macrophage by an IL-10 dependent mechanism with causes TNFR2 shedding. J. Immunol. (in press)

47. Hirsch CS, Ellner JJ, Russell DG and Rich EA (1994) Complement receptormediator uptake and tumor necrosis factor-alpha-mediated growth inhibiton of Mycobacterium tuberculosis by human alveolar macrophages. J. Immunol. 152 $743-753$

48. Berman JS, Blumenthal RL, Kornfeld H, Cook JAXCW, Vermeulen MW, Chatterjee D, Belisle JT and Fenton MJ (1996) Chemotactic activity of mycobacterial lipoarabinomannans for human blood T lymphocytes in vitro. $J$ Immunol. 156: 3828-3835
49. Moreira AL, Wang J, Tsenova-Berkova L, Hellmann W, Freedman VH and Kaplan G (1997) Sequestration of Mycobacterium tuberculosis in tight vacuoles in vivo in lung macrophages of mice infected by the respiratory route. Infect. Immun. 65: 305-308

50. Xu S, Cooper A, Sturgill-Koszycki S, van Heyningen T, Chatterjee D, Orme I, Allen $P$ and Russell DG (1994) Intracellular trafficking in Mycobacterium tuberculosis and Mycobacterium avium-infected macrophages. Cell 153: $2568-2577$

51. Molloy A, Laochumroonvorapong $P$ and Kaplan G (1994) Apoptosis, but not necrosis, of infected monocytes is coupled with killing of intracellular Bacillus Calmette-Guerin. J. Exp. Med. 180: 1499-1509

52. Lammas DA, Stober C, Harvey CJ, Kendrick N, Panchalingam $S$ and Kumararatne DS. ATP-induced killing of mycobacteria by human macrophages is mediated by purinergic $P 2 Z\left(P 2 X_{7}\right)$ receptors. Immunity $7: 433$

53. Laochumroonvorapong $P$, Paul S, Elkon KB and Kaplan $\mathrm{G}(1996) \mathrm{H}_{2} \mathrm{O}_{2}$ induces monocyte apoptosis and reduces viability of Mycobacterium avium- $M$. intracellulare within cultured human monocytes. Infect. Immun. 64: 452-459

54. Schmitt E, Meuret $G$ and Stix $L$ (1977) Monocyte recruitment in tuberculosis and sarcoidosis. Brit. J. Hematol. 35: 11-17

55. Fratazzi C, Arbeit RD, Carini C and Remold HG (1997) Programmed cell death of Mycobacterium avium serovar 4-infected human macrophages prevents mycobacteria from spreading and induces mycobacterial growth inhibition by freshly added, uninfected macrophages. J. Immunol. 158: 4320-4327

56. Piacentini M and Colizzi V (1998) 《Tissue》transglutaminase: apoptosis versus autoimmunity. Immunol. Today. (in press)

57. Zychlinsky A and Sansonetti P (1997) Apoptosis in bacterial pathogenesis. J. Clin. Invest. 100: 493-496

58. Rogers HW, Callery MP, DeckB and UnanueER (1996) Listeria monocytogenes induces apoptosis of infected hepatocytes. J. Immunol. 156: 679-684

59. Barsig J and Kaufmann SH (1997) The mechanism of cell death in Listeria monocytogenese-infected murine macrophages is distinct from apoptosis. Infect. Immun. 65: 4075-4081

60. Lindgren SW, Stojiljkovic I and Heffron F (1996) Macrophage killing is an essential virulence mechanism of Salmonella typhimurium. Proc. Natl. Acad. Sci. USA 93: 4197-4201

61. Baran J, Guzik K, Hryniewicz W, Ernst M, Flad HD and Pryjma J (1996) Apoptosis of monocytes and prolonged survival of granulocytes as a result of phagocytosis of bacteria. Infect. Immun. 64: 4242-4248

62. Chen $Y$ and Zychinsky A (1994) Apoptosis induced by bacterial pathogens. Microb. Pathogenesis. 17: 203-212

63. Kato S, Muro M, Akifusa S, Hanada N, Semba I, Fujii T, Kowashi Y and Nishihara T (1995) Evidence for apoptosis of murine macrophages by Actinobacillus actinomycetemcomitans infection. Infect. Immun. 63: 3914-3919

64. Kochi SK and Collier RJ (1993) DNA fragmentation and cytolysis in U937 cells treated with diphtheria toxin or other inhibitors of protein synthesis. Exp. Cell. Res. 208: 296-302

65. Millis SD, Boland A, Sory MP, Van der Smissen, Kerborourch C, Finlay BB and Cornelis GR (1997) Yersinia enterocolitica induces apoptosis in macrophages by a process requiring functional type III secretion and translocation mechanisms and involving YopP, presumably acting as an effector protein. Proc. Natl. Acad. Sci. USA 94: 12638-12643

66. Bayles KW, Wesson CA, Liou LE, Fox LK, Bohach GA and Trumble WR (1998) Intracellular Staphylococcus aureus escapes the endosome and induces apoptosis in epithelia cells. Infect. Immun. 66: 336-342

67. Muller A, Hacker J and Brand BC (1996) Evidence for apoptosis of human macrophage-like $\mathrm{HL}-60$ cells by Legionella pneumophila infection. Infect. Immun. 64: 4900-4906

68. Smoot DT (1997) How does Helicobacter pyloricause mucosa damage? Direct mechanisms. Gastroenterology 113: S31-S34

69. KremerL, Estaquier J, Brandt E, Ameisen JC and Locht C (1997) Mycobacterium bovis Bacillus Calmette Guerin infection prevents apoptosis of resting human monocytes. Eur. J. Immunol. 27: 2450-2456 